\title{
Assessment of Clonality in Gastrointestinal Cancer by DNA Fingerprinting
}

\author{
M. F. Fey, ${ }^{\star}$ R. A. Wells, ${ }^{\ddagger}$ J. S. Wainscoat, ${ }^{\star}$ and S. L. Thein ${ }^{\star}$ \\ ${ }^{*}$ Department of Haematology and ${ }^{\ddagger}$ Nuffield Department of Clinical Medicine, John Radcliffe Hospital, \\ Headington, Oxford OX3 9DU, United Kingdom
}

\begin{abstract}
DNA fingerprinting with three different probes $(33.15,33.6$, and $\alpha$-globin 3HVR) was investigated as a method for the determination of clonality in gastrointestinal tumors. In $29 / 44$ carcinomas the tumor DNA showed clonal somatic mutations that were not seen in the corresponding peripheral blood and normal mucosa samples. The changes consisted of either novel fingerprint bands, losses of bands, or both. The probe 33.15 yielded the highest rate of abnormal DNA fingerprints $(21 / 44$ carcinomas). Sequential use of the probes increased the number of cases where clonal fingerprint markers could be detected. One out of five colorectal adenomas also showed a clonal loss of a fingerprint band. In two cases of gastric cancer, DNA from the metastatic tumor had a different DNA fingerprint from that found in the primary carcinoma. DNA fingerprinting offers a novel approach to determining clonality in tumors and may prove useful for the study of tumor progression.
\end{abstract}

\section{Introduction}

The determination of clonality of human tumors has important implications for the mechanisms of carcinogenesis. The discovery that a tumor has a monoclonal composition is consistent with a mutational theory of carcinogenesis: a mutation occurring within a single cell results in a tumor composed entirely of the progeny of that cell $(1,2)$. Most human tumors investigated to date have been shown to be monoclonal (3-6). However, hereditary tumors such as hereditary neurofibromas may be of multiclonal origin since all the cells from which they originate have the potential to develop into tumors $(7,8)$. Other mechanisms, for example aberrant differentiation processes, may also result in neoplasms with a polyclonal composition (9). The practical value of clonality determination is well illustrated by the lymphoproliferative disorders where the distinction can be made between a reactive process (polyclonal) and a neoplastic process (monoclonal) $(10,11)$.

The assessment of clonality in tumor cell populations has traditionally depended on one of three approaches: the expression of a single allele of glucose-6-phosphate dehydrogenase within the tumor of a female patient heterozygous for an enzyme polymorphism (12); the determination that only a single Ig light chain (either lambda or kappa) is expressed on

Address correspondence and reprint requests to Dr. M. F. Fey, Department of Medicine, Inselspital, CH-3010 Bern, Switzerland.

Received for publication 18 February 1988 and in revised form 14 June 1988.

\section{J. Clin. Invest.}

(C) The American Society for Clinical Investigation, Inc.

$0021-9738 / 88 / 11 / 1532 / 06 \$ 2.00$

Volume 82, November 1988, 1532-1537 the surface of neoplastic B cells in lymphoproliferative disorders (13); and the demonstration of a specific cytogenetic abnormality (14). More recently, the techniques of molecular genetics have enlarged the scope of these methods. For example, X-linked restriction fragment length polymorphisms can be used to study the clonality of tumors in a higher percentage of female patients than is feasible using the glucose-6-phosphate dehydrogenase isoenzymes (6). The use of DNA probes for $\mathrm{Ig}$ and $\mathrm{T}$ cell receptor genes has permitted clonality to be assessed in a wide variety of lymphoid neoplasms including $T$ cell tumors not expressing Ig light chains. Nevertheless, Xlinked restriction fragment length polymorphisms are limited to tumors of female patients, while Ig and T cell receptor gene probes are limited to lymphopoietic tumors.

DNA fingerprinting enables the detection of many unlinked autosomal hypervariable region (HVR) ${ }^{1}$ loci simultaneously (15-17). These loci have a particularly high mutation rate, possibly because they are hotspots for meiotic or mitotic recombination or sister chromatid exchange (15). The combination of these two properties makes DNA fingerprint analysis an attractive approach for the detection of clonal somatic mutations in tumors. In a preliminary study of DNA fingerprints in a variety of human cancers, 10 of 35 cases (29\%) screened by the probe 33.15 showed somatic DNA fingerprint mutations, including three of eight gastrointestinal cancers with novel bands (18). These mutations must be present in clonal cell populations since otherwise they would not be detectable by Southern blotting. We decided to explore the value of DNA fingerprinting as a new technique to assess clonality in human tumors by studying gastrointestinal tumors, since they have been demonstrated to be clonal neoplasms (5). We now present a detailed analysis of gastric and colonic cancers, comparing the DNA fingerprints of peripheral blood, normal mucosa, and corresponding tumor samples from 42 patients using three DNA fingerprint probes, 33.15, 33.6, and $\alpha$-globin 3'HVR. A clonal abnormality was detected in two-thirds of all the cases, suggesting that DNA fingerprinting may prove to be a valuable new approach for determining clonality in human tumors.

\section{Methods}

Patients. 42 patients ( 26 males and 16 females) with gastrointestinal carcinomas were studied. Two patients each had two separate colorectal carcinomas, making the total number of tumors 44 (Table I). The cases included 10 gastric carcinomas and 34 colorectal adenocarcinomas. Among the gastric cancers material from regional lymph node metastases was available in two cases. In four patients with colorectal carcinomas, adenomas were also studied. We also collected samples from five resected ileocecal segments involved with Crohn's disease as additional controls.

1. Abbreviation used in this paper: HVR, hypervariable region. 
Table I. Somatic Changes in DNA Fingerprints of Gastrointestinal Cancers

\begin{tabular}{|c|c|c|c|c|c|c|c|c|c|c|c|}
\hline \multirow[b]{3}{*}{ Patient } & \multirow[b]{3}{*}{ Tumor } & \multirow[b]{3}{*}{ Dukes } & \multicolumn{9}{|c|}{ Probes } \\
\hline & & & \multicolumn{3}{|c|}{33.6} & \multicolumn{3}{|c|}{33.15} & \multicolumn{3}{|c|}{$\alpha$-Globin 3'HVR } \\
\hline & & & NC & NB & LB & $\mathrm{NC}$ & NB & LB & $\mathrm{NC}$ & NB & LB \\
\hline 1 & AC stomach, mucinous & & & 1 & & & 1 & & 0 & & \\
\hline $2 \mathrm{a}$ & AC stomach, primary & & 0 & & & 0 & & & 0 & & \\
\hline b & metastasis & & & 1 & & 0 & & & 0 & & \\
\hline $3 a$ & AC stomach, primary & & 0 & & & $x$ & 1 & & 0 & & \\
\hline b & metastasis & & & 1 & & $x$ & 1 & & & 1 & \\
\hline 4 & AC stomach & & 0 & & & & & 1 & 0 & & \\
\hline 5 & CA stomach, scirrhous & & 0 & & & 0 & & & 0 & & \\
\hline 6 & AC stomach & & 0 & & & & & 1 & 0 & & \\
\hline 7 & AC stomach & & & 1 & & & 1 & & 0 & & \\
\hline 8 & CA stomach, scirrhous & & & 1 & & 0 & & & 0 & & \\
\hline 9 & CA stomach, scirrhous & & 0 & & & $\times$ & & 1 & 0 & & \\
\hline 10 & AC stomach, mucinous & & & & 1 & & 1 & & 0 & & \\
\hline 11 & AC cecum & $\mathrm{C}$ & 0 & & & 0 & & & 0 & & \\
\hline $12 \mathrm{a}$ & AC sigmoid colon & B & 0 & & & & 1 & & 0 & & \\
\hline b & AC cecum & B & 0 & & & 0 & & & 0 & & \\
\hline 13 & $\mathrm{AC}$ cecum & A & & & 1 & 0 & & & & & 1 \\
\hline 14 & AC cecum & $\mathrm{C}$ & 0 & & & 0 & & & 0 & & \\
\hline $15 \mathrm{a}$ & $\mathrm{AC}$ cecum & B & & 1 & & 0 & & & 0 & & \\
\hline b & Adenoma, tubular & & & & 1 & 0 & & & 0 & & \\
\hline 16 & $\mathrm{AC}$ cecum & B & & 1 & & & 2 & & & 1 & \\
\hline 17 & $\mathrm{AC}$ ascend colon & B & & 1 & & & 1 & & 0 & & \\
\hline $18 \mathrm{a}$ & $\mathrm{AC}$ ascend colon & B & 0 & & & & & 1 & 0 & & \\
\hline $\mathrm{b}$ & Adenoma, tubular & & 0 & & & 0 & & & 0 & & \\
\hline 19 & $\mathrm{AC}$ ascend colon & $\mathrm{C}$ & & & 1 & & & 1 & & & 2 \\
\hline 20 & AC transverse colon & $\mathrm{C}$ & 0 & & & 0 & & & 0 & & \\
\hline $21 \mathrm{a}$ & AC sigmoid colon & B & 0 & & & 0 & & & 0 & & \\
\hline b & Adenoma, tubular & & 0 & & & 0 & & & 0 & & \\
\hline c & Adenoma, tubular & & 0 & & & 0 & & & 0 & & \\
\hline 22 & AC sigmoid colon & $\mathrm{C}$ & & & 1 & 0 & & & 0 & & \\
\hline 23 & AC sigmoid colon & B & 0 & & & 0 & & & 0 & & \\
\hline 24 & AC sigmoid colon & B & & 1 & & 0 & & & 0 & & \\
\hline 25 & AC sigmoid colon & $\mathrm{C}$ & 0 & & & & 1 & & 0 & & \\
\hline $26 \mathrm{a}$ & AC sigmoid colon & A & 0 & & & 0 & & & 0 & & \\
\hline b & Adenoma, adenovillous & & 0 & & & 0 & & & 0 & & \\
\hline 27 & AC sigmoid colon & $\mathrm{D}$ & 0 & & & 0 & & & 0 & & \\
\hline 28 & AC sigmoid colon & B & 0 & & & & & 1 & 0 & & \\
\hline 29 & AC sigmoid colon & B & 0 & & & 0 & & & 0 & & \\
\hline 30 & AC sigmoid colon & $\mathrm{C}$ & 0 & & & & 1 & 1 & 0 & & \\
\hline 31 & AC sigmoid colon & B & 0 & & & 0 & & & 0 & & \\
\hline 32 & $\mathrm{AC}$ rectum & B & 0 & & & 0 & & & 0 & & \\
\hline 33 & $\mathrm{AC}$ rectum & B & 0 & & & 0 & & & 0 & & \\
\hline 34 & $\mathrm{AC}$ rectum & B & 0 & & & 0 & & & & & 1 \\
\hline 35 & $\mathrm{AC}$ rectum & B & 0 & & & & 1 & & 0 & & \\
\hline 36 & AC rectum & $\mathrm{C}$ & & 1 & 1 & & & 1 & 0 & & \\
\hline $37 \mathbf{a}$ & AC rectum & B & & & 1 & & & 1 & & & 1 \\
\hline b & AC sigmoid colon & A & 0 & & & 0 & & & & & 1 \\
\hline 38 & $\mathrm{AC}$ rectum & $\mathrm{C}$ & 0 & & & 0 & & & 0 & & \\
\hline 39 & $\mathrm{AC}$ rectum & B & $\times$ & & 1 & & & 2 & 0 & & \\
\hline 40 & $\mathrm{AC}$ rectum & $\mathrm{C}$ & & 1 & 1 & + & & & & 1 & \\
\hline 41 & AC rectum & $\mathrm{C}$ & 0 & & & & 1 & & 0 & & \\
\hline 42 & AC colon (liver metastasis) & $\mathrm{D}$ & & 1 & & 0 & & & 0 & & \\
\hline
\end{tabular}

AC, a carcinoma; NC, no change in tumor DNA fingerprint; NB, novel band in tumor DNA fingerprint; LB, lost band in tumor DNA fingerprint. + , tumor DNA fingerprint shows gain in intensity of a band present in constitutional DNA; $\times$, intensity shifts between bands in tumor DNA fingerprint. 
All specimens were obtained fresh at surgery and the regions of tissue where tumor material was taken for DNA extraction were also subjected to microscopical study. The diagnoses of the tumors were made by histological examination of paraffin-embedded tissue sections and were classified according to the World Health Organization International Reference Center (19). In the five cases of Crohn's disease, specimens of inflammatory lesions (confirmed by histological examination) were collected. In each case samples of peripheral venous blood and normal gastric or colorectal mucosa were collected for comparison. Specimens of normal mucosa were taken as far away as possible (at least $5 \mathrm{~cm}$ ) from the nearest adenoma or carcinoma.

DNA analysis. High molecular weight DNA was extracted by routine methods from peripheral blood leukocytes and from tissue material that had been ground to powder in liquid nitrogen (20). Equivalent amounts $(10 \mu \mathrm{g})$ of DNA from peripheral blood, normal mucosa, and tumors or inflammatory lesions in the case of Crohn's disease were digested with the restriction enzyme Hinf I (Boehringer-Mannheim GmbH, Mannheim, FRG; and Anglian Biotechnology Ltd., Colchester, Essex, UK) according to the manufacturer's guidelines. The digested DNA samples of each case were electrophoresed in adjacent tracks in $22-\mathrm{cm}$-long $1.0 \%$ (wt/vol) agarose gels at $2.0 \mathrm{~V} / \mathrm{cm}$ for 16 or $40 \mathrm{~h}$. The fragments were then denatured in alkali and transferred to nylon filters (Hybond-N; Amersham International, Amersham, UK) as described (21).

DNA probes and hybridization procedures. The minisatellite probes (both M13 recombinants containing the respective minisatellite plus flanking human DNA) were 33.6, a 720-nucleotide Hae III fragment subcloned into the Sma I site of M13mp8, and 33.15, a 592-nucleotide Pst I/Aha III fragment subcloned into M13mp19 DNA digested with Pst I and Sma I (16). The $\alpha$-globin $3^{\prime}$ HVR probe was a 4-kb Hinf I fragment from the recombinant pSEA 1 which includes an HVR $3^{\prime}$ of the $\alpha$-globin gene cluster (22). Under hybridization conditions of low stringency this probe has also been shown to provide an individual-specific DNA fingerprint unrelated to the patterns revealed by probes 33.6 and 33.15 (Thein, S. L., unpublished results).

The minisatellite probes 33.6 and 33.15 were labeled with $\left[{ }^{32} \mathrm{P}\right]-$ deoxycytidine triphosphate as described previously $(15,16)$. The $\alpha$ globin $3^{\prime}$ HVR probe was labeled with $\left[{ }^{32} \mathrm{P}\right]$ deoxycytidine triphosphate by the random-hexamer-primer method (23). For hybridization with the M13 recombinant probes filters were prehybridized in $50 \%$ formamide, $3 \times$ standard saline citrate (SSC) (150 mM sodium chloride, 15 $\mathrm{mM}$ sodium citrate, $\mathrm{pH} 7.0$ ), $0.2 \% \mathrm{SDS}$, and $50 \mu \mathrm{g} / \mathrm{ml}$ heparin and hybridized at $37^{\circ} \mathrm{C}$ in the same buffer with the addition of $5 \%$ dextran sulfate and $200 \mu \mathrm{g} / \mathrm{ml}$ heparin. They were washed in $1 \times$ SSC and $0.1 \%$ SDS at $61^{\circ} \mathrm{C}$. For DNA fingerprinting with the $\alpha$-globin $3^{\prime}$ HVR probe filters were prehybridized and hybridized at $61^{\circ} \mathrm{C}$ in $1.5 \times \operatorname{SSPE}(270$

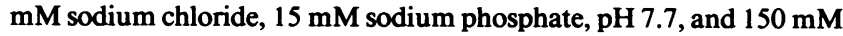
EDTA), $0.5 \%$ Cadbury's marvel milk powder, $1 \%$ SDS, and $6 \%$ polyethylene glycol 8,000. The washes were done in $1 \times$ SSC and $0.1 \%$ SDS at $50^{\circ} \mathrm{C}$. The filters were subjected to autoradiography at $-70^{\circ} \mathrm{C}$ for 2-7 d with and without intensifying screens. Losses of fingerprint bands in tumor DNA were ascertained by overexposure of the filters with respect to the other bands.

Statistical methods used included Fisher's exact test (two-tailed) and the Poissonian distribution as appropriate.

\section{Results}

In each case the DNA fingerprints detected in DNA from peripheral blood leukocytes and normal gastrointestinal mucosa were indistinguishable. Similarly, no differences were observed between the DNA fingerprints of the normal DNA and the DNA samples extracted from inflammatory lesions in five cases of Crohn's disease. The abnormalities observed in the tumor DNA fingerprints chiefly included novel bands, loss of bands seen in the corresponding normal DNA, and shifts in hybridization intensity between bands in the tumor DNA compared with normal DNA (Table I and Fig. 1). The abnormalities were confirmed with repeat experiments using a gross excess of restriction enzyme ( $50 \mathrm{U}$ enzyme per $\mu \mathrm{g}$ of DNA).

The overall rates of somatic DNA fingerprint mutations in colorectal carcinomas classified by Dukes staging were as follows: stage A, 2/3; stage B, 11/18; stage C, 7/11; stage D, 1/2. Tumors in Dukes' stages A and B do not show a higher frequency of abnormal fingerprints than tumors in stages $\mathrm{C}$ and $\mathrm{D}(P>0.20)$.

The probes $33.15,33.6$, and $\alpha$-globin $3^{\prime} \mathrm{HVR}$ detected, respectively, the following mean number of bands in constitutional DNA: 18, 23, and 11. The probe 33.15 detected a slightly greater number of changes in the primary carcinomas (12 novel bands, 11 lost bands) than 33.6 (10 novel bands, 8 lost bands) but this is not statistically significant. However, both these probes detected a greater number of changes than the $\alpha$-globin $3^{\prime}$ HVR probe (two novel bands, six lost bands, $P$ $<0.005$ ), which partly relates to the increased number of bands they detect. To determine whether the sequential use of several probes significantly increases the proportion of cases with abnormal tumor DNA fingerprints the cases were analyzed as shown in Fig. 2. The first probe used was 33.15, followed by 33.6 and $\alpha$-globin $3^{\prime}$ HVR. 21/44 carcinomas (48\%) were abnormal on investigation with $33.15 .6 / 23$ tumors with normal 33.15 fingerprints and 10/21 tumors with abnormal 33.15 fingerprints were found to be abnormal on sequential analysis with the probe 33.6. There was no statistically significant difference between these two groups $(P>0.02)$. The $\alpha$ globin $3^{\prime} \mathrm{HVR}$ probe detected two more cases with abnormalities that had previously been found to be normal with both 33.6 and 33.15 . There were 15 carcinomas (34\%) that did not show any changes with the three probes.

Table II provides a more detailed breakdown of the observed numbers of changes in the tumors compared with the number of expected changes. The number of cases observed with zero, one, or two novel bands or losses did not differ significantly from the numbers expected conforming to a Poissonian distribution. Thus these results are compatible with the hypothesis that each fingerprint band in a tumor has an independent chance of being affected.

Four of the five adenomas showed normal DNA fingerprints. However, one adenoma showed a loss of a band that was present both in the constitutional DNA and the DNA of the colonic carcinoma (case 15). Two patients (Table I, 12 and 37) had two separate colorectal tumors. In case 12 one tumor (12b) showed a normal DNA fingerprint, whereas the other (12a) had a novel band. Case 37 showed losses of bands with all three probes in one tumor (37a) and with the $\alpha$-globin $3^{\prime} H V R$ only in the other (37b). In two gastric cancers (Table I, 2 and 3) DNA extracted from metastatic tumor in lymph nodes could be studied. In case 2 the primary carcinoma had a normal fingerprint, whereas the metastasis had a novel band. In case 3 the metastasis had novel bands with all three probes, none of which were shared by the primary tumor, which in turn showed a novel band detected by 33.15 .

\section{Discussion}

We have shown that screening the DNA of gastrointestinal cancers with a panel of three fingerprint probes provides clonal 


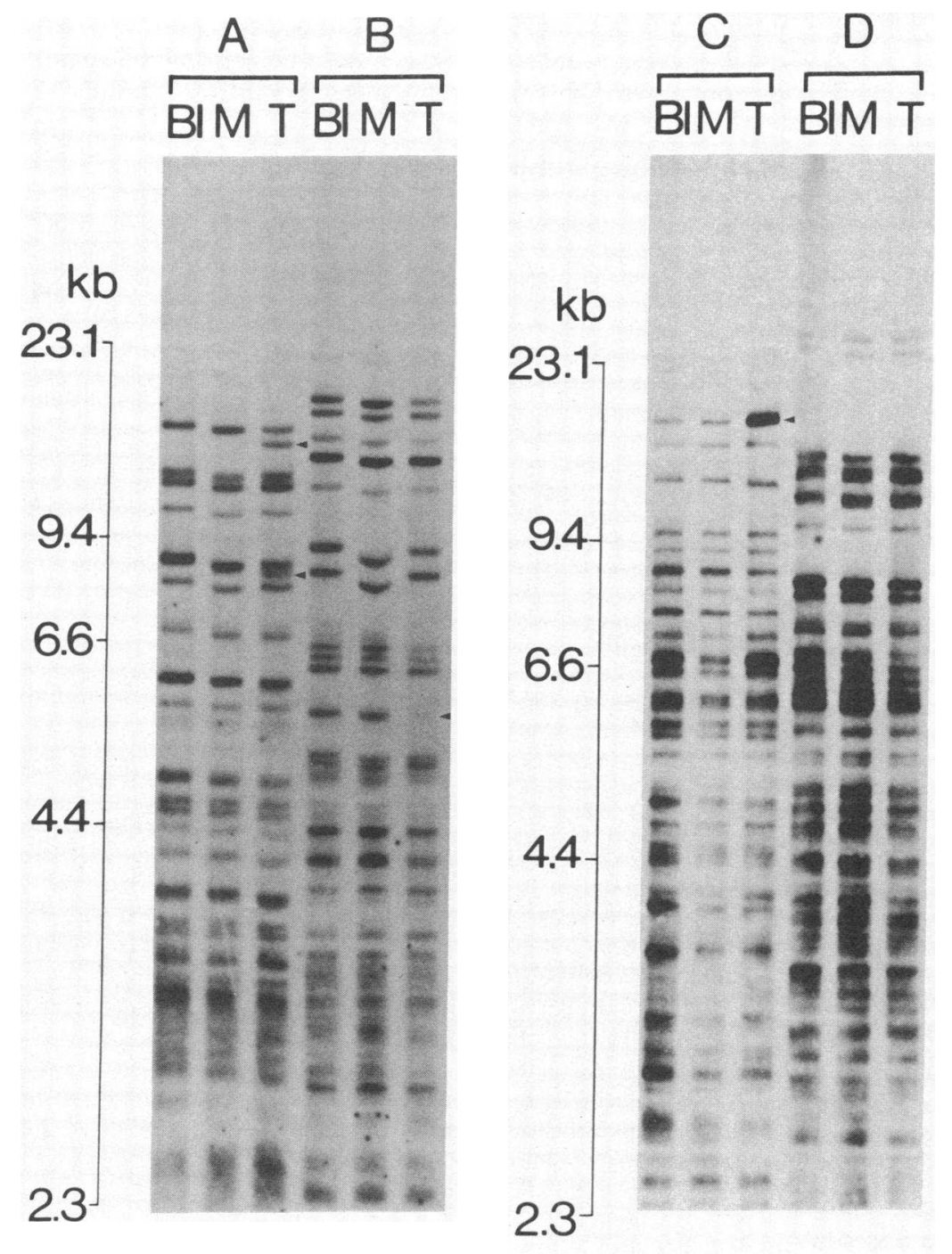

Figure 1. Autoradiograph of DNA fingerprints in colorectal tumors. In each case DNA from peripheral blood $(B 1)$, normal mucosa $(M)$, and tumor $(T)$ were digested with Hinf $I$. The Southern blot filters were hybridized to the probe 33.15. The fragment sizes of the molecular marker are indicated in kilobases. Patients: $A$, case 16 , adenocarcinoma of cecum; $B$, case 28 , adenocarcinoma of sigmoid colon; $C$, case 40 , adenocarcinoma of rectum; $D$, case 20 , adenocarcinoma of transverse colon. Clonal markers are indicated by arrows. Note that $A$ (case 16) shows two novel bands in the tumor fingerprint while $B$ (case 28) shows a loss of a band. $C$ (case 40 ) shows increased intensity of a fingerprint band in the tumor and $D$ (case 20) shows the normal fingerprint of the carcinoma. markers in a high proportion (66\%) of these tumors. The finding that none of our cases showed any differences between the DNA fingerprints of peripheral blood leukocytes and normal

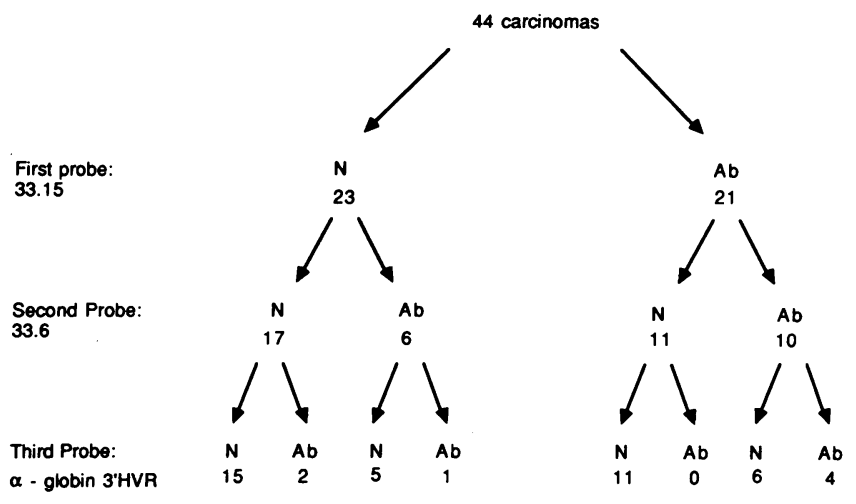

Figure 2. Detection of clonal markers in gastrointestinal tumors by DNA fingerprinting. Cumulative analysis using three fingerprint probes. $N$, normal DNA fingerprint in tumor DNA; $A b$, abnormal fingerprint in tumor DNA. For comments and statistical analysis see Results. mucosa further confirms that these changes seen in the carcinomas are somatic mutations. As expected, none of the cases of Crohn's disease was found to show any mutations in DNA extracted from inflammatory lesions. Interestingly, sequential screening of tumors with several probes does increase the proportion of cases in which clonal markers can be defined. The search for clonal markers in a given case might best be begun by using the probes 33.15 or 33.6 , since the chances of finding clonal markers on Southern blots are greater with these two probes than with the $\alpha$-globin $3^{\prime} H V R$ probe. An advantage of DNA fingerprinting in the assessment of clonality in tumors is that a particular blot can be probed sequentially with several probes, thus increasing the rate of detection of clonal markers. Also, studies of clonality can be performed irrespective of the patient's sex. Other methods for the determination of clonality are all associated with some difficulties, such as the technical problems of cytogenetics in solid tumors and the limitation of the methods based on X-linked protein or gene mosaicisms to females $(6,12)$; therefore, we hope that DNA fingerprinting of human tumors will become a valuable additional technique.

The precise mechanisms responsible for the alterations in the tumor DNA fingerprints are unknown. Unequal mitotic exchange of genetic material as well as DNA slippage during 
Table II. Distribution of Novel Bands and Losses of Bands in 44 Tumors Detected by Three Fingerprint Probes

\begin{tabular}{|c|c|c|c|c|c|c|c|}
\hline \multirow{3}{*}{$\begin{array}{l}\text { Change in } \\
\text { tumor } \\
\text { fingerprint }\end{array}$} & \multirow{3}{*}{$\begin{array}{c}\text { No. of } \\
\text { lost/new } \\
\text { bands }\end{array}$} & \multicolumn{6}{|c|}{$\begin{array}{l}\text { No. of changes in tumor fingerprints observed and } \\
\text { expected }{ }^{*} \text { with three different probes }\end{array}$} \\
\hline & & \multicolumn{2}{|c|}{33.15} & \multicolumn{2}{|c|}{33.6} & \multicolumn{2}{|c|}{$\begin{array}{c}\alpha \text {-Globin } \\
3^{\prime} \text { HVR }\end{array}$} \\
\hline & & Obs. & Exp.* & Obs. & Exp.* & Obs. & Exp.* \\
\hline \multirow[t]{5}{*}{ Novel bands } & 0 & 33 & 34.5 & 34 & 35.0 & 42 & 42.0 \\
\hline & 1 & 10 & 9.1 & 10 & 8.0 & 2 & 1.9 \\
\hline & 2 & 1 & 1.2 & 0 & 0.9 & 0 & 0.04 \\
\hline & 3 & 0 & 0.1 & 0 & 0.07 & 0 & 0 \\
\hline & & 44 & & 44 & & 44 & \\
\hline \multirow[t]{5}{*}{ Lost bands } & 0 & 34 & 34.0 & 36 & 36.7 & 39 & 38.4 \\
\hline & 1 & 9 & 8.6 & 8 & 6.7 & 4 & 5.2 \\
\hline & 2 & 1 & 1.1 & 0 & 0.6 & 1 & 0.36 \\
\hline & 3 & 0 & 0.09 & 0 & 0.04 & 0 & 0.02 \\
\hline & & 44 & & 44 & & 44 & \\
\hline
\end{tabular}

* The expected number of bands lost or gained in the tumors was calculated according to the Poissonian distribution for the observed frequencies.

replication could result in novel bands or losses of bands (24). Changes in DNA methylation patterns have been shown to occur in colorectal cancer (25), which may alter Hinf I cleavage sites. However, abnormal tumor DNA fingerprints were confirmed in both our previous (18) and present reports (data not shown) using restriction enzymes such as Alu I or Hae III, which are not methylation sensitive (26). For future studies we recommend that Alu I be used as the enzyme of first choice. Human tumors have been found to show clonal losses of chromosomal regions (5), which might account for band losses in the fingerprint. We suspect that in most cases DNA fingerprints detect widespread loss of relatively small chromosomal regions, since otherwise we would have observed a considerably higher number of cases with loss of more than one band.

Comparison of DNA fingerprints from primary carcinomas and metastatic tumors is particularly interesting. In our cases the DNA from metastatic tumors showed new bands that were present neither in the constitutional DNA nor in the primary tumor, with the implication that the metastatic tumor cells underwent clonal somatic mutations not present in the original tumor. Changes in the clonal composition of tumors have been thought to represent changes in the growth characteristics of particular subpopulations of tumor cells, for example dormant cells in primary tumors which grow rapidly in metastases $(9,27)$. These observations suggest DNA fingerprinting would be useful in studying tumor progression and relapse at a molecular level. Similarly, genetic changes could be followed by serial DNA analysis of tumor cells propagated in culture.

Although we report the use of DNA fingerprints here as clonal markers in gastrointestinal carcinomas, we have found such markers in a variety of other neoplasias, for example acute myeloblastic leukemias (unpublished observations), malignant lymphomas, and breast carcinomas (18). Unlike Ig or $\mathrm{T}$ cell receptor gene rearrangements, clonal changes in DNA fingerprints of tumors do not seem to be associated with particular types of cancers, and their use in benign and malignant neoplasms of different tissue origins warrants further study.

\section{Acknowledgments}

We are indebted to Dr. A. J. Jeffreys for providing the probes 33.6 and 33.15 (both subjected to patent application) and to Dr. D. R. Higgs for the $\alpha$-globin 3'HVR probe. We are grateful to Dr. T. E. A. Peto for his help with the statistical analysis and to Professor Sir David J. Weatherall for his support and encouragement. We would also like to acknowledge the help of the surgeons and pathologists who collected the tumor samples.

M. F. Fey is a Research Fellow of the Swiss National Science Foundation and The Royal Society, and is also supported by the Swiss Cancer Leagues. R. A. Wells is a Rhodes Scholar, S. L. Thein is a Wellcome Trust Senior Research Fellow, and J. S. Wainscoat is supported by the Leukaemia Research Fund of the United Kingdom.

\section{References}

1. Knudson, A. G., Jr. 1971. Mutation and cancer: statistical study of retinoblastoma. Proc. Natl. Acad. Sci. USA. 68:820-823.

2. Knudson, A. G., Jr. 1985. Hereditary cancer, oncogenes and antioncogenes. Cancer Res. 45:1437-1443.

3. Fialkow, P. J., S. M. Gartler, and A. Yoshida. 1967. Clonal origin of chronic myelocytic leukaemia in man. Proc. Natl. Acad. Sci. USA. 58:1468-1471.

4. Smith, J. W., D. E. Towsend, and R. S. Sparkes. 1971. Genetic variants of glucose-6-phosphate dehydrogenase in the study of carcinoma of the cervix. Cancer (Phila.). 28:529-532.

5. Fearon, E. R., S. R. Hamilton, and B. Vogelstein. 1987. Clonal analysis of human colorectal tumors. Science (Wash. DC). 238:193197.

6. Vogelstein, B., E. R. Fearon, S. R. Hamilton, and A. P. Feinberg. 1985. Use of restriction fragment length polymorphisms to determine the clonal origin of human tumors. Science (Wash. DC). 227:642-645.

7. Fialkow, P. J., R. W. Sagebiel, S. M. Gartler, and D. L. Rimoin. 1971. Multiple cell origin of hereditary neurofibromas. $N$. Engl. $J$. Med. 284:298-300.

8. Hsu, S. H., G. D. Luk, A. J. Krush, S. R. Hamilton, and H. H. Hoover, Jr. 1983. Multiclonal origin of polyps in Gardner syndrome. Science (Wash. DC). 221:951-953.

9. Alexander, P. 1985. Do cancers arise from a single transformed cell or is monoclonality of tumours a late event in carcinogenesis. $\mathrm{Br}$. $\mathrm{J}$. Cancer. 51:453-457.

10. Arnold, A., J. Cossman, A. Bakhshi, E. S. Jaffe, T. A. Waldmann, and S. J. Korsmeyer. 1983. Immunoglobulin-gene rearrangements as unique clonal markers in human lymphoid neoplasms. $N$. Engl. J. Med. 309:1593-1599.

11. Waldmann, T. A., M. M. Davis, K. F. Bongiovanni, and S. J. Korsmeyer. 1985. Rearrangements of genes for the antigen receptor on $\mathrm{T}$ cells as markers of lineage and clonality in human lymphoid neoplasms. N. Engl. J. Med. 313:776-783.

12. Beutler, E., Z. Collins, and L. E. Irwin. 1967. Value of genetic variants of glucose-6-phosphate dehydrogenase in tracing the origin of malignant tumors. N. Engl. J. Med. 276:389-391.

13. Aisenberg, A. C. 1978. Cell-surface markers in lymphoproliferative disease. $N$. Engl. J. Med. 304:331-336.

14. Yunis, J. J. 1983. The chromosomal basis of human neoplasia. Science (Wash. DC). 221:227-235.

15. Jeffreys, A. J., V. Wilson, and S. L. Thein. 1985. Individual-specific "fingerprints" of human DNA. Nature (Lond.). 316:76-79.

16. Jeffreys, A. J., V. Wilson, and S. L. Thein. 1985. Hypervariable "minisatellite" regions in human DNA. Nature (Lond.). 314:67-73.

17. Jeffreys, A. J., V. Wilson, S. L. Thein, D. J. Weatherall, and B. A. J. Ponder. 1986. DNA "fingerprints" and segregation analysis of 
multiple markers in human pedigrees. Am. J. Hum. Genet. 39:11-24.

18. Thein, S. L., A. J. Jeffreys, H. C. Gooi, F. Cotter, J. Flint, N. T. J. O'Connor, D. J. Weatherall, and J. S. Wainscoat. 1987. Detection of somatic changes in human cancer DNA by DNA fingerprint analysis. Br. J. Cancer. 55:353-356.

19. Morson, B. C., and L. H. Sobin. 1976. Histological typing of intestinal tumours. Int. Histol. Classif. Tumours. World Health Organization, Geneva. 15:1-69.

20. Maniatis, T., E. F. Fritsch, and J. Sambrook. 1982. Molecular Cloning: A Laboratory Manual. Cold Spring Harbor Laboratories, Cold Spring Harbor, NY. 545 pp.

21. Southern, E. M. 1975. Detection of specific sequences among DNA fragments separated by gel electrophoresis. J. Mol. Biol. 98:503-517.

22. Jarman, A. P., R. D. Nicholls, D. J. Weatherall, J. B. Clegg, and D. R. Higgs. 1986. Molecular characterisation of a hypervariable re- gion downstream of the human $\alpha$-globin gene cluster. EMBO (Eur. Mol. Biol. Organ.) J. 5:1857-1863.

23. Feinberg, A. P., and B. A. Vogelstein. 1983. A technique for radiolabelling DNA restriction endonuclease fragments to high specific activity. Anal. Biochem. 132:6-13.

24. Smith, G. P. 1976. Evolution of repeated DNA sequences by unequal crossover. Science (Wash. DC). 191:528-535.

25. Goelz, S. E., B. Vogelstein, S. R. Hamilton, and A. P. Feinberg. 1985. Hypomethylation of DNA from benign and malignant human colon neoplasms. Science (Wash. DC). 228:187-190.

26. McClelland, M., and M. Nelson., 1985. The effect of site specific methylation on restriction endonuclease digestion. Nucleic Acids Res. 13(Suppl.): r201.

27. Woodruff, M. F. A., J. D. Ansell, G. M. Forbes, J. C. Gordon, D. I. Burton, and H. S. Micklem. 1982. Clonal interaction in tumours. Nature (Lond.) 299:822-824. 